\title{
Comentarios
}

\section{ARENA ante los resultados de las elecciones}

Por diversos medios se ha filtrado que en ARENA los ánimos están caldeados. Eso no es para menos, si se toma en cuenta que muchos de sus miembros se sienten abrumados con los resultados de las últimas elecciones legislativas y municipales. Para estos areneros, la situación es francamente alarmante y, por lo mismo, urge de soluciones prontas y audaces. Otros miembros de ARENA, sin caer en las posturas dramáticas de los primeros, reconocen que las cosas no le salieron bien al partido en las elecciones y que hay que aceptar que se trató de una derrota inobjetable. Para estos últimos son necesarios ciertos cambios partidarios, pero los mismos deben ser efectuados con la debida calma, evitando las salidas abruptas. Finalmente, están quienes creen que no hay nada de que preocuparse, pues el partido continúa gozando del poder de siempre, aunque levemente alterado por la pérdida de 36 alcaldías y una cuota menor de diputados en relación con el FMLN, su principal rival político.

Así, pues, los resultados de las elecciones del 12 de marzo han llevado a un importante sector de ARENA a asumir como tema de discusión el fracaso electoral del partido. Ciertamente, vistos los números con frialdad, la derrota del partido de derecha no es tan absoluta como a primera vista pudo parecer; por lo mismo, el triunfo del FMLN no es tan arrollador como en un principio creyeron sus simpatizantes más envalentonados con los logros electorales efemelenistas. ARENA ha perdido importantes bastiones municipales - claves para detener el deterioro de su hegemonía-, no pudo contener el influjo arrollador de Héctor Silva -influjo que apunta a convertirlo en un serio as- pirante a la presidencia de la república en el año 2004- y tiene dos diputados menos que el FMLN. De eso no se sigue, sin embargo, que ARENA va a estar a la zaga del FMLN: antes bien, en las decisiones fundamentales, ambos partidos van a tener que llegar a acuerdos ineludibles o van a tener que buscar el respaldo del gran ganador de las elecciones: el Partido de Conciliación Nacional (PCN).

La tesis del equilibrio entre las dos principales fuerzas políticas del país es la que mejor responde a la configuración del escenario político tras las elecciones del 12 de marzo. Otra cosa es que ese equilibrio se incline ligeramente a favor del FMLN o que, en virtud de ello, algunos de sus miembros gusten llamar al partido de izquierda "la primera fuerza política del país". El FMLN será la primera fuerza política, pero no es una fuerza política con capacidad de dominio absoluto ni en el ámbito legislativo ni en el ámbito municipal. Creer lo contrario es pecar de una imperdonable falta de realismo, cuyas consecuencias prácticas pueden ser graves por las expectativas que se puedan despertar entre aquellos ciudadanos que esperan, a partir del ascenso electoral del FMLN, una transformación radical en el rumbo de la economía.

Con todo, una cosa son los resultados efectivos, así como la lectura más o menos objetiva que se pueda hacer de los mismos, y otra muy distinta son las reacciones de los afectados, así como la interpretación interesada que éstos puedan hacer de aquéllos. Nadie dice que una lectura interesada de determinados datos electorales $\longrightarrow$ de otra indole- no pueda ser más o menos objetiva, pero 
para ello debe asumir con honestidad - y en toda su contundencia - los datos que la realidad plantea. ¿Encontramos en ARENA esta honestidad con los datos de la realidad? ¿Han mostrado sus dirigentes disposición para asumirlos en toda su contundencia? Más específicamente, ¿cuáles han sido las reacciones más significativas generadas al interior de ARENA, en tomo a los resultados de las elecciones?

Para avanzar hacia una respuesta tentativa de esas interrogantes, es útil ensayar una tipología' de las reacciones suscitadas al interior de ARE$\mathrm{NA}$, ante los resultados de las elecciones. Sin mucho esfuerzo, se pueden distinguir cuatro posturas, que se corresponden con las tres casillas de la tipología que proponemos. En la primera, se podría ubicar lo que podemos denominar la reacción emotiva ante los datos electorales; en la segunda casilla, la reacción despreocupada; en la tercera, la reacción dramática; y en la cuarta, la reacción moderada. A continuación, haremos una revisión somera de cada una de ellas.

Reacción emotiva. Esta fue la reacción inicial de importantes figuras de ARENA, al conocerse los primeros datos globales de las elecciones. No cabe duda de que esa reacción estuvo muy marcada por el calor de una batalla recién librada y su característica más llamativa fue la de una compunción, que casi rayaba en lo patético. La angustia y aflicción en los rostros de figuras duras de ARENA -hombres que nunca lloran o se lamentan, hombres acostumbrados a hacer temblar a otros con su voz y su porte- era algo más que esa angustia y esa aflicción que expresan quienes han perdido a un ser querido: se trataba de una angustia y una aflicción ante el amor propio herido.

En esa reacción inicial, los dirigentes de ARENA manifestaron, sin pudor alguno, el pesar que les causaba ver su orgullo maltratado por un electorado que no se daba cuenta del mal que se estaba haciendo a sí mismo al no darle sus votos al partido que podía sacarlos de la miseria. Los ros- tros compungidos, las miradas aletargadas, los ojos llorosos... Basta dar un vistazo a las fotografías a todo color de los matutinos de los días 13 y 14 de marzo para caer en la cuenta de cuán honda era la pena que embargaba a los principales líderes de ARENA. Y ello no dejaba de resultar chocante, cuando se contrastaba con las poses previas a las elecciones de los ahora compungidos, poses aclamadas en su momento por los mismos medios de comunicación, que ahora mostraban justo lo opuesto de ellas: bravura de machos, con botas vaqueras y gruesas hebillas, convertida en lloriqueo infantil. Elegancia en el porte, con los trajes de la confección más fina, convertida en frente sudorosa y ojos vidriosos. Risa burlona y prepotente, convertida en mueca adolorida. Simplemente patético, y no porque sea malo o condenable que al más plantado se le salgan de vez en cuando unos lagrimones o se muestre compungido, sino porque hay cosas más importantes para llorar y compungirse que unas elecciones. Pero qué se le va a hacer. Así es el amor propio de algunos.

Evidentemente, después de los desbordes emocionales ante una tragedia, viene el momento de la meditación sobre lo sucedido, la ponderación de su alcance real y de los desafíos que supone tanto en el plano personal como grupal. ¿Ha entrado la cúpula de ARENA en esta etapa o todavía sus miembros están desbordados por las emociones ante el fracaso electoral? Al parecer, sin que todavía los ánimos estén totalmente calmados - para que esa calma llegue quizás habrá que esperar que pase un buen rato-, en ARENA ha llegado el momento de meditar y asumir los desafíos correspondientes. Por lo ménós, así lo dejan entrever algunas tomas de postura de miembros claves del partido. Son estas tomas de postura que se han sucedido después de la crisis emotiva inicial las que se exponen a continuación, siempre en el espíritu tipológico, que guía estas reflexiones.

Reacción despreocupada. Esta es una de las reacciones que se han suscitado en ARENA tras la situación de crisis emocional. Es una reacción pro-

1. Se trata de una tipologia: de un ejercicio para identificar unos ciertos "tipos ideales", que permitan comprender los comportamientos y las reacciones de los miembros de ARENA ante los resultados electorales. En el ámbito de lo concreto, determinados miembros de ARENA no tienen necesariamente que expresar en forma exclusiva un tipo ideal particular, sino que pueden ser portavoces varios de ellos. El tipo ideal - dice Max Weber- es, en lo esencial, una "construcción conceptual para la mediación y caracterización sistemática de conexiones individuales, es decir, significativas en su singularidad". Ver M. Weber, Ensayos sobre metodología sociológica, Buenos Aires, 1973, p. 89; W.G. Runciman, Crítica a la filosofia de las ciencias sociales de Max Weber, México, 1976. 
pia de quienes ven los resultados electorales con cierta frialdad y que incluso creen que el partido no ha salido debilitado para nada con ellos. No hay seguridad alguna de que quienes asi opinan no lo hagan por un mero afán retórico y que, en el fondo, estén seriamente preocupados por los logros obtenidos en las elecciones. Sin embargo, se cuidan de no hablar de una derrota electoral. Han insistido en que lo sucedido no supone una merma de poder para ARENA ni mucho menos; desde su punto de vista, el partido sigue tan fuerte como antes de las elecciones, pues lo que éste ha perdido no lo ha ganado el FMLN, cosa para ellos de suma importancia para sostener su posición.

La consecuencia práctica que se sigue de esa lectura es que ARENA debe continuar tal cual, con su misma cúpula dirigente y su misma estrategia política. En esta óptica, los resultados de las elecciones constituyen, a lo sumo, un leve traspiés, cuyas razones deben ser buscadas fuera del partido, quizás en un electorado que no entiende bien sus intereses $\longrightarrow$ que espera beneficios inmediatos de un partido ocupado en tareas más trascendentales- o en las trampas que el FMLN le puso al partido, específicamente con la huelga del ISSS que, según algunos voceros de ARENA, dañó la imagen del gobiemo y del partido. Si no hay fracaso, no hay responsables. Si la gente no entiende las bondades que se le ofrecen, peor para la gente. Como dijo Luis Cardenal, al saber de su derrota ante Héctor Silva, son los habitantes de San Salvador los que se pierden la oportunidad de tenerlo como jefe edilicio; a él, quien, en opinión de una de las estrellas del periodismo criollo, estaba llamado a ser, sin discusión alguna, un buen alcalde.

Reacción dramática. Pero los despreocupados no están solos; tienen una contraparte crítica dentro del partido, formada por aquellos que se sitúan en el extremo opuesto a su posición. Quienes integran esta contraparte perciben en los resultados electorales un fracaso político estrepitoso de ARENA. No sólo un fracaso en la forma de llevar la campaña electoral, sino también un fracaso en la conducción del partido. Para quienes así opinan, no se trata de un problema de los electores, sino de un problema intemo de ARENA, cuyos éxitos

político-electorales ya no pueden darse por supuestos. Los dramáticos son quienes más han llamado la atención de los medios de comunicación, ávidos a más no poder de todo aquello que huela a escándalo. Y ello no es gratuito: no sólo han sentado en el banquillo de los acusados a su propio partido, sino que han puesto de manifiesto las fisuras internas que lo atraviesan.

El planteamiento básico de una postura como la apuntada se puede formular así: si las razones del fracaso se encuentran dentro del partido, lo que se impone es su reestructuración drástica $e$ inmediata. Y esa reestructuración exige, ante todo, la deducción de responsabilidades, pues son los responsables de la derrota quienes tienen que ceder los espacios de poder que ocupan. En otras palabras, tienen que rodar cabezas. ¿Cuáles? Las de quienes concentran en sus manos el poder partidario, pues lo que se hizo o dejó de hacerse fue decisión de ellos. Estamos, pues, ante una posición catastrófica que, de sumar más adeptos a sus filas, va a causar jaleos intemos en ARENA, a partir de los cuales o bien salen triunfantes o bien embarcan al partido en un proceso de transformaciones necesarias, pero inciertas. De momento, parecen no estar dispuestos a quedarse callados; hacen ruido en un partido que tiene por norma el silencio acerca de lo que sucede en su interior. Otros que gustaban del ruido, como Orlando de Sola y Alfredo Mena Lagos, tuvieron que hacerlo desde fuera del partido. ¿Correrán la misma suerte los ruidosos de ahora?

Reacción moderada. En una dinámica como la que se ha suscitado en ARENA tras las elecciones 
del 12 de marzo no pueden faltar los moderados, es decir, quienes ven en los resultados electorales una derrota de ARENA, pero no absoluta, sino más bien relativa. Aceptan que es preocupante que ARENA haya perdido alrededor de 36 alcaldías y que el FMLN tenga dos diputados más, pero no ven en ello un motivo suficiente para comenzar una desesperada cacería de brujas dentro del partido. Aceptan que hubo fallos en la estrategia política seguida y que ha habido desaciertos en la conducción partidaria, pero no dejan de señalar que el electorado a veces espera más —en beneficios inmediatos- de lo que efectivamente puede dársele. En otras palabras, proponen tomarse las cosas con calma, conservar lo mejor que el partido tiene, respetar los liderazgos establecidos y, en ese marco, hacer los cambios que la situación exige. En su perspectiva, de lo que se trata es de aceptar, sin mayor drama, que el electorado no está satisfecho con el desempeño de ARENA y que ello hace necesarios algunos cambios al interior del partido. Pero su supuesto es que esa insatisfacción del electorado tiene poco que ver con desaciertos generalizados: más bien se trata de fallos puntuales - una decisión equivocada, un gesto inoportuno, una demanda no resuelta - que, al ser corregidos, van a permitir al partido recuperar el respaldo electoral perdido.

De momento, han ganado más prensa los alarmistas. Sus tomas de posición ya han ocupado sendos espacios en los medios de prensa escrita. Pero no es seguro que su punto de vista termine por ser aceptado por la gran mayoría de miembros de ARENA. Y es que para ellos no puede pasar desapercibido lo problemático que puede resultar un proceso de transformaciones partidarias de largo aliento. Un proceso de esa naturaleza se traduciría en una lucha interna, que podría terminar debilitando al partido en un grado extremo. $Y$ eso, seguramente, no lo desea ni el arenero más frustrado con los resultados de las elecciones ni el más resentido con el predominio del grupo Cristiani. Así que a lo mejor los alarmistas van a tener que dar marcha atrás en sus ímpetus transformadores, pues, en caso contrario, corren el riesgo no sólo de quedarse solos, sino de ser excluidos del partido.
Por lo demás, entre los despreocupados y los moderados son posibles las coincidencias de fondo, sobre todo en lo que atañe al mantenimiento de los liderazgos tradicionales. Y es que lo que más temen quienes creen que en ARENA todo marcha con normalidad es que se ponga en cuestión la cuota de poder que concentran en sus manos. Si ésta se da por supuesta, quizás no tengan reparo en aceptar algunos cambios importantes - sugeridos por los moderados - en la estrategia política del partido y por qué no en la conducción del mismo. En este sentido, es muy probable que unos y otros -aceptados unos acuerdos básicos - terminen por rechazar las soluciones radicales y a quienes las abanderan.

En resumen, los areneros que ven en los resultados de las elecciones un fracaso rotundo del partido - y que, en consecuencia, claman por una deducción inmediata de responsabilidades - tienen pocas posibilidades de hacer prevalecer sus puntos de vista. Tienen más oportunidad de hacerse sentir los que sostienen una posición moderada, aunque cautelosa, ante los logros de ARENA en las elecciones del 12 de marzo. Y es que, aunque ARENA no haya fracasado estrepitosamente, ello no quiere decir que no haya sufrido un importante revés. Algunas responsabilidades tendrán que deducirse. De llegar a aglutinar en sus filas a importantes sectores de ARENA, ¿hasta dónde van a estar dispuestos a llegar los moderados? No se sabe. De momento, todos - hasta quienes se mostraron en un principio más vociferantes ante la derrota electoral- parecen haber acordado tomarse las cosas con calma, por lo menos de puertas afuera. De puertas adentro, quién sabe lo que estará sucediendo. De todos modos, no es la primera vez que el partido tiene que habérselas consigo mismo, lo cual casi siempre se ha traducido en la salida de los inconformes. ¿Sucederá lo mismo en esta ocasión? ¿Caerán viejos reinados? ¿O todos harán las pases por el bien de la Alianza Republicana Nacionalista y el espíritu anticomunista que la alienta y sostiene en los tiempos difíciles?

Luis Armando González San Salvador, 28 de marzo de 2000 